Article

\title{
Bifunctionalized Allenes. Part XVI. Synthesis of 3-Phosphoryl-2,5-dihydrofurans by Coinage Metal-Catalyzed Cyclo-isomerization of Phosphorylated $\alpha$-Hydroxyallenes
}

\author{
Valerij Ch. Christov ${ }^{\dagger} * *$, Ismail E. Ismailov ${ }^{\dagger}$ and Ivaylo K. Ivanov ${ }^{\dagger}$ \\ Department of Organic Chemistry \& Technology, Faculty of Natural Sciences, \\ Konstantin Preslavsky University of Shumen, 115, Universitetska str., BG-9712 Shumen, Bulgaria; \\ E-Mails: ismail78@mail.bg (I.E.I.); iivanov@shu-bg.net (I.K.I.) \\ $\dagger$ These authors contributed equally to this work. \\ * Author to whom correspondence should be addressed; E-Mail: vchristo@shu-bg.net; \\ Tel.: +359-54-830-495 (ext. 222 or 155); Fax: +359-54-830-371.
}

Academic Editor: Derek J. McPhee

Received: 23 March 2015 / Accepted: 17 April 2015 / Published: 21 April 2015

\begin{abstract}
Phosphorylated $\alpha$-hydroxyallenes 1 and $\mathbf{2}$ were smoothly converted into the corresponding 2,5-dihydrofurans $\mathbf{3}$ and $\mathbf{4}$ in an 5-endo-trig cycloisomerization reaction by using $5 \mathrm{~mol} \%$ of coinage metal salts as catalyst. Experimental conditions such as the type of the solvent, the reaction temperature, the mol \% and the type of the catalyst were optimized. This mild and efficient cyclization method can be applied to dimethyl 1-hydroxyalkyl-alka-1,2-dienephosphonates 1 and 2-diphenylphosphinoyl-2,3-dien-1-ols $\mathbf{2 a - c}$ and 3-diphenylphosphinoyl-3,4-dien-2-ols 2d,e, furnishing 3-phosphorylated 2,5-dihydrofurans 3 and $\mathbf{4}$ in very good yields.
\end{abstract}

Keywords: phosphorylated $\alpha$-hydroxyallenes; cycloisomerization; coinage metal catalysts; 2,5-dihydrofurans

\section{Introduction}

2,5-Dihydrofurans and their derivatives are structural subunits frequently found in a wide variety of natural products which find application as flavor and fragrance compounds and pharmaceuticals [1-3] 
and represent pivotal structural elements in a wide variety of different biologically active molecules. For instance, they can be found in mycotoxins such as verrucosidine [4] and the structurally related citreoviridine [5], as well as vitamin A metabolites [6], polyether antibiotics [7,8], spiroketals [9] and even amino acids [10]. 2,5-Dihydrofurans are also important intermediates in organic synthesis due to the presence of the $\mathrm{C}=\mathrm{C}$ bond as well as the five-membered ring. Consequently, much attention has been paid to the development of efficient and diverse synthetic methods for construction of this five-membered ring system [11-13].

Transition metal-catalyzed cyclization of functionalized allenes bearing a nucleophilic center has attracted considearble attention in recent years [14]. Particularly, the cyclization reactions of allenols catalyzed by $\mathrm{Ag}(\mathrm{I})$ [15-18], $\mathrm{Hg}$ (II) [19,20], $\mathrm{Pd}(0)$ [21-23], $\mathrm{Pd}(\mathrm{II})$ [24,25], or $\mathrm{Ru}(\mathrm{III})$ [26,27] have become quite useful methodologies for the synthesis of five-, or six-membered oxygen-containing heterocycles. Krause's group has reported a highly efficient and stereoselective synthesis of 2,5-dihydrofurans by $\mathrm{Au}(\mathrm{I})$ and $\mathrm{Au}(\mathrm{III})$-catalyzed [28-33] cycloisomerization of $\alpha$-hydroxyallenes [34-36]. Moreover, the method is not restricted to the cycloisomerization of $\alpha$-hydroxyallenes to 2,5-dihydrofurans [34,35], rather, it was recently extended by Krause's group to the corresponding endo-cyclization of $\beta$-hydroxyallenes [37], $\alpha$-/ $\beta$-aminoallenes [37-39], and $\alpha$-thioallenes [40] to the corresponding five- or six-membered $O-,, N$, or $S$-heterocycles. The method of choice, however, is the use of transition metal catalysts since this combines high reactivities and excellent yields with a tolerance to many functional groups.

On the other hand, the literature data on the reactions of phosphorylated allenes with electrophilic reagents reveal that the reactions proceed with cyclization of the allenic system bearing the phosphoryl group $(\mathrm{O}=\mathrm{P}-\mathrm{C}=\mathrm{C}=\mathrm{C})$ to give heterocyclic compounds in most cases and the outcome depends on the structure of the starting allenic compound as well as the type of electrophile used [41-44]. Several diethylphosphono-substituted $\alpha$-allenic alcohols [45] and glycols [46] were prepared by Brel [47,48] directly from alcohols by Horner-Mark rearrangement of unstable propargylic phosphites and used as starting materials for study of the cyclization in the presence of $\mathrm{AgNO}_{3}[46,47,49]$ and $\mathrm{CuCl}_{2}[48]$.

Our long-standing research program focuses on the development of efficient cyclization reactions of 1,1- [50,51] and 1,3-bifunctionalized allenes [52,53]. More specifically, our attention is drawn to phosphorylated hydroxyallenes as 1,1-bifunctionalized allenes that comprise a phosphoryl and a hydroxyalkyl group. The applications of these groups as temporary transformers of chemical reactivity of the allenic system in the synthesis of eventually heterocyclic compounds are of particular interest. These molecules can be considered a combination of an allenephosphonate or allenyl phosphine oxide and a hydroxyallene and they are supposed to have different reactivity profiles in cycloisomerization reactions. Our recent research has led to a significant result, whereby we have developed a convenient and efficient method for the regioselective synthesis of phosphorylated $\alpha$-hydroxyallenes using an atom economical [2,3]-sigmatropic rearrangement [54]. In this paper, we present recent results of ongoing studies dedicated towards the optimization of the experimental conditions and the catalyst efficiency in the coinage metal salts-catalyzed cycloisomerization of $\alpha$-hydroxyalkyl-allenephosphonates and phosphine oxides to 3-phosphorylated 2,5-dihydrofurans, which strongly improve the scope of this method. 


\section{Results and Discussion}

In addition to our previously reported preparation [55] of 2,5-dihydro-1,2-oxaphospholes by electrophilic cyclization of the 1-hydroxyalkyl-allenephosphonates $\mathbf{1}$ and allenyl phosphine oxides 2 due to the participation of the phosphonate neighboring group in the 5-endo-trig cyclization, we carried out the cycloisomerization reaction of the abovementioned compounds $\mathbf{1}$ and $\mathbf{2}$ in the presence of coinage metal salts as catalysts. Our initial work began with the cycloisomerization reaction of the model $\alpha$-hydroxyalkyl-allenephosponate $\mathbf{1 a}$ with $\mathrm{AgNO}_{3}$ in order to optimize the reaction conditions such as the influence of the solvent, the reaction temperature, the mol \% and the type of the catalyst. The reaction occurred with formation of the dimethyl (5-ethyl-5-methyl-2,5-dihydrofuran-3-yl) phosphonate (3a, Scheme 1). The results are summarized in Table 1.

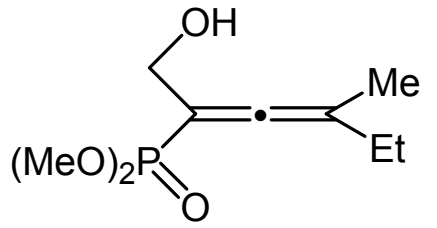

$1 \mathrm{a}$

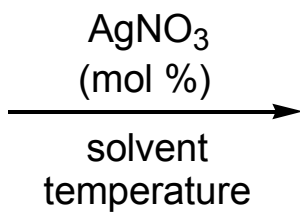

temperature

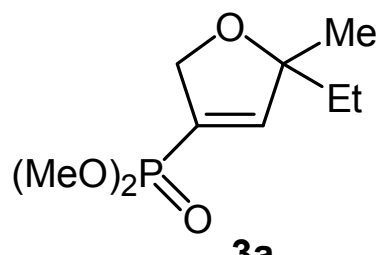

$3 a$

Scheme 1. $\mathrm{AgNO}_{3}$-catalyzed cycloisomerization of the model dimethyl 1-hydroxymethyl3-methylpenta-1,2-dienephosphonate (1a).

Table 1. Optimization of the $\mathrm{AgNO}_{3}$-catalyzed cycloisomerization of the model dimethyl 1-hydroxymethyl-3-methylpenta-1,2-dienephosphonate (1a).

\begin{tabular}{|c|c|c|c|c|}
\hline Entry & Solvent ${ }^{a}$ & Reaction temperature $\left({ }^{\circ} \mathrm{C}\right)$ & $\mathrm{AgNO}_{3}(\mathrm{~mol} \%)$ & Yield $^{\mathrm{b}}(\%)$ \\
\hline 1 & $\mathrm{ClCH}_{2} \mathrm{CH}_{2} \mathrm{Cl}$ & -20 & 10 & 41 \\
\hline 2 & $\mathrm{ClCH}_{2} \mathrm{CH}_{2} \mathrm{Cl}$ & 0 & 5 & 55 \\
\hline 3 & $\mathrm{ClCH}_{2} \mathrm{CH}_{2} \mathrm{Cl}$ & $\mathrm{rt}$ & 5 & 63 \\
\hline 4 & $\mathrm{ClCH}_{2} \mathrm{CH}_{2} \mathrm{Cl}$ & reflux & 5 & 45 \\
\hline 5 & $\mathrm{CHCl}_{3}$ & $\mathrm{rt}$ & 5 & 58 \\
\hline 6 & $\mathrm{EtOH}$ & $\mathrm{rt}$ & 5 & 46 \\
\hline 7 & $\mathrm{MeCN}$ & $\mathrm{rt}$ & 5 & 45 \\
\hline 8 & THF & $\mathrm{rt}$ & 5 & 40 \\
\hline 9 & toluene & $\mathrm{rt}$ & 5 & 28 \\
\hline 10 & acetone & $\mathrm{rt}$ & 5 & 51 \\
\hline 11 & acetone $/ \mathrm{H}_{2} \mathrm{O}$ & $\mathrm{rt}$ & 5 & 75 \\
\hline 12 & acetone $/ \mathrm{H}_{2} \mathrm{O}$ & $\mathrm{rt}$ & 10 & 77 \\
\hline 13 & $\mathrm{CH}_{2} \mathrm{Cl}_{2}$ & -20 & 5 & 72 \\
\hline 14 & $\mathrm{CH}_{2} \mathrm{Cl}_{2}$ & $\mathrm{rt}$ & 5 & $84^{\mathrm{c}}$ \\
\hline 15 & $\mathrm{CH}_{2} \mathrm{Cl}_{2}$ & $\mathrm{rt}$ & 10 & 82 \\
\hline
\end{tabular}

a Reaction was carried out in the appropriate solvent $(10 \mathrm{~mL}) ;{ }^{b}$ Yields determined by ${ }^{1} \mathrm{H}$ and ${ }^{31} \mathrm{P}-\mathrm{NMR}$ analysis; ${ }^{\mathrm{c}}$ Isolated yield by chromatographic purification on silica gel.

At the very beginning, the reaction occurred in 1,2-dichloroethane at $-20{ }^{\circ} \mathrm{C}$ with $10 \mathrm{~mol} \%$ of catalyst (Table 1, entry 1). The yield was $41 \%$. On the other hand, when we used $5 \mathrm{~mol} \%$ of catalyst to carry out the reaction at $0{ }^{\circ} \mathrm{C}$ or room temperature in the same solvent the yield increased considerably 
(Table 1, entries 2 and 3). Lower yield was obtained at reflux in the same solvent (Table 1, entry 4). It is obvious that the optimal temperature for the cycloisomerization reaction of compound 1a is room temperature. The use of polar solvents such as chloroform, ethanol, acetonitrile and THF at room temperature with $5 \mathrm{~mol} \% \mathrm{AgNO}_{3}$ produces the product in relatively good yields (Table 1, entries 5-8). A lower yield occurred in toluene (Table 1, entry 9). When the solvent was a mixture of acetone and $\mathrm{H}_{2} \mathrm{O}$ [15] at room temperature the yield was $77 \%$ with $5 \mathrm{~mol} \%$ of catalyst (Table 1, entries 11 and 12). The data confirm that the optimal conditions for cycloisomerization of model compound 1a (Table 1, entry 14) are methylene chloride, $5 \mathrm{~mol} \%$ catalyst and room temperature. We found that reactions occurring at low or high reaction temperatures different from the optimum afford lower yields (Table 1, entries 2, 4 and 13). We also saw a lower yield when we used $10 \mathrm{~mol} \%$ of catalyst at room temperature in dichloromethane (Table 1, entry 15). The type of catalyst and its influence on the yields of the cycloisomerization products of the $\alpha$-hydroxyalkyl-allenephosphonates $\mathbf{1 a}-\mathbf{e}$ was also of great interest to us. We thus conducted a series of experiments to optimize the reaction conditions of the model compound 1a (Scheme 2). We applied the following coinage metal salts as catalysts: $\mathrm{AgNO}_{3}$, $\mathrm{AgClO}_{4}, \mathrm{AuCl}, \mathrm{AuCl}_{3}, \mathrm{ZnCl}_{2}, \mathrm{NiCl}_{2}, \mathrm{PtCl}_{2}, \mathrm{SnCl}_{2}, \mathrm{AlCl}_{3}, \mathrm{PdCl}_{2}, \mathrm{Pd}\left(\mathrm{PPh}_{3}\right)_{4}, \mathrm{CuCl}_{2}, \mathrm{CuCl}, \mathrm{CuBr}$, and $\mathrm{CuI}$. The data reveal that both $\mathrm{Au}$ and $\mathrm{Ag}$ are excellent catalysts. $\mathrm{Pd}, \mathrm{Cu}(\mathrm{II})$ and $\mathrm{Pt}$ are very good catalysts for our experiments. It becomes obvious that $\mathrm{Zn}, \mathrm{Ni}, \mathrm{Sn}$ and $\mathrm{Al}$ are relatively good catalysts. It is the $\mathrm{Cu}(\mathrm{I})$ catalysts that are bad. Table 2 presents the characteristics of all the above-mentioned catalysts in the cycloisomerization reaction of the model compound 1a.

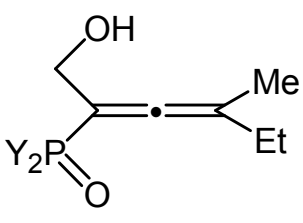

1a, $Y=\mathrm{MeO}$

2a, $Y=P h$

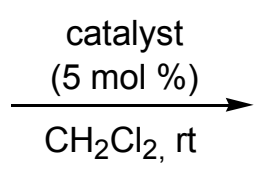

$=\mathrm{MeO}$

4a, $\mathrm{Y}=\mathrm{Ph}$

Scheme 2. Coinage metal-catalyzed cycloisomerization of the model dimethyl 1-hydroxymethyl-3-methylpenta-1,2-dienephosphonate $\mathbf{1 a}$ and the model 2-diphenylphosphinoyl-4-methylhexa-2,3-dien-1-ol 2a.

The next step in our study was to explore the possibilities of the cycloisomerization reactions of the $\alpha$-hydroxyalkyl-allenyl phosphine oxides $\mathbf{2 a}-\mathbf{e}$ synthesized by us. At the very beginning, we used 2-diphenylphosphinoyl-4-methylhexa-2,3-dien-1-ol (2a) as a model compound. The optimal cycloisomerization conditions included dichloromethane as solvent, $5 \mathrm{~mol} \%$ catalyst and room temperature. The reaction occurred via an 5-endo-trig cyclization to give 4-(diphenylphosphinoyl)-2ethyl-2-methyl-2,5-dihydrofuran (4a, Scheme 2). We performed a series of experiments with the sole intention of determining the best catalysts bearing in mind two criteria-highest yield and shortest reaction time. The model compound $\mathbf{2 a}$ reacts with the catalysts shown in Table 2, in which the yields obtained and the reaction time of the preparation of isomer $\mathbf{4 a}$ are presented. The experimental data reveals that the best catalytic characteristics correspond to $\mathrm{Au}, \mathrm{Ag}$ and $\mathrm{Pd}$ catalysts (Table 2). The $\mathrm{Cu}(\mathrm{II}), \mathrm{Zn}$ and Pt catalysts that show very good results. The Sn, Al and Ni are relatively good. 
Table 2. Optimization of the coinage metal-catalyzed cycloisomerization of the model compound 1a and the model dien-1-ol 2a.

\begin{tabular}{cccccc}
\hline \multirow{2}{*}{ Entry } & \multirow{2}{*}{ Catalyst } & \multicolumn{2}{c}{ Reaction time $^{\text {a }}$ (min) } & \multicolumn{2}{c}{ Yield $^{\mathbf{b}} \mathbf{( \% )}$} \\
\cline { 3 - 6 } & & $\mathbf{1 a}$ & $\mathbf{2 a}$ & $\mathbf{1 a}$ & $\mathbf{2 a}$ \\
\hline 1 & $\mathrm{AuCl}$ & 20 & 30 & 97 & 91 \\
2 & $\mathrm{AuCl}$ & 30 & 35 & 94 & 89 \\
3 & $\mathrm{AgClO}_{4}$ & 30 & 55 & $83^{\mathrm{c}}$ & $85^{\mathrm{c}}$ \\
4 & $\mathrm{AgNO}_{3}$ & 50 & 65 & 80 & 80 \\
5 & $\mathrm{PdCl}_{2}$ & 100 & 115 & 73 & 80 \\
6 & $\mathrm{Pd}\left(\mathrm{PPh}_{3}\right)_{4}$ & 105 & 120 & 74 & 77 \\
7 & $\mathrm{CuCl}_{2}$ & 115 & 110 & 77 & 74 \\
8 & $\mathrm{PtCl}_{2}$ & 135 & 180 & 66 & 78 \\
9 & $\mathrm{ZnCl}_{2}$ & 160 & 135 & 50 & 75 \\
10 & $\mathrm{NiCl}_{2}$ & 225 & 395 & 53 & 36 \\
11 & $\mathrm{SnCl}_{2}$ & 310 & 255 & 38 & 57 \\
12 & $\mathrm{AlCl}_{3}$ & 345 & 340 & 34 & 32 \\
13 & $\mathrm{CuCl}_{1}$ & 530 & 635 & 27 & 27 \\
14 & $\mathrm{CuBr}$ & 545 & 690 & 29 & 22 \\
15 & $\mathrm{CuI}$ & 600 & 725 & 24 & 23 \\
\hline
\end{tabular}

a On the average; ${ }^{\mathrm{b}}$ Yields determined by ${ }^{1} \mathrm{H}$ - and ${ }^{31} \mathrm{P}-\mathrm{NMR}$ analysis; ${ }^{\mathrm{c}}$ Isolated yield by chromatographic purification on silica gel.

The investigation on the cycloisomerization reaction of the synthesized series of $\alpha$-hydroxyalkylallenephosphonates 1a-e was intended to be systematical. We applied the optimized reaction temperature, type of the solvent and molar ratio of the catalyst conditions in regard to the substrate. Having in mind that gold catalysts are expensive and sensitive to moisture, we decided to use $\mathrm{AgClO}_{4}$ as a main catalyst in cycloisomerization reaction in order to extend our study (Scheme 3). The results are explicit enough - a catalytic 5-endo-trig cycloisomerization occurs and the hydroxy group participates as an internal nucleophile to give the 2,5-dihydrofuran-3-yl phosphonates 3 in very good yields.

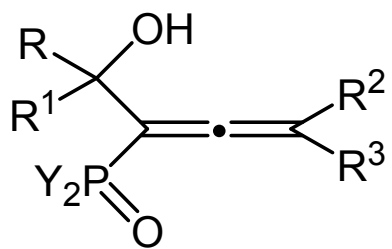

1,2
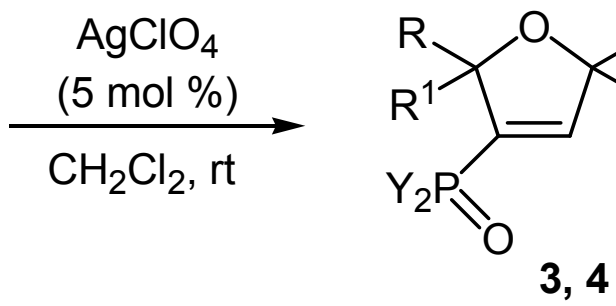

Scheme 3. $\mathrm{AgClO}_{4}-$ Catalyzed cycloisomerization of the phosphorylated $\alpha$-hydroxyallenes $\mathbf{1}$ and $\mathbf{2}$.

Our study was systematized also on the cycloisomerization of a series of $\alpha$-hydroxyalkyl-allenyl phosphine oxides 2a-e in methylene chloride at room temperature (Scheme 3). Moreover, it was the $\mathrm{AgClO}_{4}$ catalyst, which is easily accessible and relatively good, that was used in our research. The results are undisputable - the 3-diphenylphosphinoyl-2,5-dihydrofurans $\mathbf{4}$ are produced as a result of the participation of the neighboring hydroxy group as an internal nucleophile in the cyclization 
process. Table 3 shows the reaction times and yields of the cycloisomerization reaction of the $\alpha$-hydroxyalkyl-allenephosphonates $\mathbf{1 a}-\mathbf{e}$ and allenyl phosphine oxides $\mathbf{2 a}-\mathbf{e}$.

Table 3. $\mathrm{AgClO}_{4}$-Catalyzed cycloisomerization of the phosphorylated $\alpha$-hydroxyallenes $\mathbf{1}$ and $\mathbf{2}$.

\begin{tabular}{ccccccccc}
\hline Entry & Allene & $\mathbf{Y}$ & $\mathbf{R}$ & $\mathbf{R}^{\mathbf{1}}$ & $\mathbf{R}^{\mathbf{2}}$ & $\mathbf{R}^{\mathbf{3}}$ & Reaction time $^{\mathbf{a}}(\mathbf{m i n})$ & Product, Yield $^{\mathbf{b}} \mathbf{( \% )}$ \\
\hline 1 & $\mathbf{1 a}$ & $\mathrm{MeO}$ & $\mathrm{H}$ & $\mathrm{H}$ & $\mathrm{Me}$ & $\mathrm{Et}$ & 30 & $\mathbf{3 a}, 83$ \\
2 & $\mathbf{1 b}$ & $\mathrm{MeO}$ & $\mathrm{H}$ & $\mathrm{H}$ & $\mathrm{Me}$ & $\mathrm{Bu}$ & 35 & $\mathbf{3 b}, 75$ \\
3 & $\mathbf{1 c}$ & $\mathrm{MeO}$ & $\mathrm{H}$ & $\mathrm{H}$ & $-\left(\mathrm{CH}_{2}\right)_{5^{-}}$ & 41 & $\mathbf{3 c}, 73$ \\
4 & $\mathbf{1 d}$ & $\mathrm{MeO}$ & $\mathrm{H}$ & $\mathrm{Me}$ & $\mathrm{Me}$ & $\mathrm{Et}$ & 33 & $\mathbf{3 d}, 77$ \\
5 & $\mathbf{1 e}$ & $\mathrm{MeO}$ & $\mathrm{Me}$ & $\mathrm{Me}$ & $\mathrm{Me}$ & $\mathrm{Bu}$ & 40 & $\mathbf{3 e}, 74$ \\
6 & $\mathbf{2 a}$ & $\mathrm{Ph}$ & $\mathrm{H}$ & $\mathrm{H}$ & $\mathrm{Me}$ & $\mathrm{Et}$ & 55 & $\mathbf{4 a}, 85$ \\
7 & $\mathbf{2 b}$ & $\mathrm{Ph}$ & $\mathrm{H}$ & $\mathrm{H}$ & $\mathrm{Me}$ & $\mathrm{Bu}$ & 58 & $\mathbf{4 b}, 85$ \\
8 & $\mathbf{2 c}$ & $\mathrm{Ph}$ & $\mathrm{H}$ & $\mathrm{H}$ & $-\left(\mathrm{CH}_{2}\right)_{5^{-}}$ & 75 & $\mathbf{4 c}, 82$ \\
9 & $\mathbf{2 d}$ & $\mathrm{Ph}$ & $\mathrm{H}$ & $\mathrm{Me}$ & $\mathrm{Me}$ & $\mathrm{Et}$ & 57 & $\mathbf{4 d}, 84$ \\
10 & $\mathbf{2 e}$ & $\mathrm{Ph}$ & $\mathrm{Me}$ & $\mathrm{Me}$ & $\mathrm{Me}$ & $\mathrm{Bu}$ & 64 & $\mathbf{4 e}, 82$ \\
\hline \multicolumn{7}{c}{}
\end{tabular}

\section{Experimental Section}

\subsection{General Information}

All new synthesized compounds were purified by column chromatography and characterized on the basis of NMR, IR, and microanalytical data. NMR spectra were recorded on DRX Bruker Avance-250 (Bruker BioSpinGmbH, Karlsruhe, Germany) $\left({ }^{1} \mathrm{H}\right.$ at $250.1 \mathrm{MHz},{ }^{13} \mathrm{C}$ at $62.9 \mathrm{MHz},{ }^{31} \mathrm{P}$ at $101.2 \mathrm{MHz}$ ) and Bruker Avance II+600 (Bruker BioSpinGmbH) $\left({ }^{1} \mathrm{H}\right.$ at $600.1 \mathrm{MHz},{ }^{13} \mathrm{C}$ at $150.9 \mathrm{MHz},{ }^{31} \mathrm{P}$ at $242.9 \mathrm{MHz}$ ) spectrometers for solutions in $\mathrm{CDCl}_{3}$. All ${ }^{1} \mathrm{H}$ - and ${ }^{13} \mathrm{C}-\mathrm{NMR}$ experiments were measured referring to the signal of internal TMS and ${ }^{31} \mathrm{P}-\mathrm{NMR}$ experiments were measured referring to the signal of external $85 \% \mathrm{H}_{3} \mathrm{PO}_{4} . J$ values are given in Hertz. IR spectra were recorded with an Afinity-1 FT-IR spectrophotometer (Shimadzu, Tokyo, Japan). Elemental analyses were carried out by the Microanalytical Service Laboratory of Faculty of Chemistry and Pharmacy, University of Sofia, Sofia, Bulgaria, using Vario EL3 CHNS(O) (Elementar Analysensysteme, Hanau, Germany). Column chromatography was performed on Kieselgel F25460 (70-230 mesh ASTM, 0.063-0.200 nm, Merck, Darmstadt, Germany). Reactions were carried out in oven dried glassware under an argon atmosphere and exclusion of moisture. All compounds were checked for purity on Kieselgel F25460 TLC plates (Merck).

\subsection{Starting Materials}

The starting phosphorylated $\alpha$-hydroxyallenes $\mathbf{1}$ and $\mathbf{2}$ were prepared according to the established procedure [54]. $\mathrm{CH}_{2} \mathrm{Cl}_{2}$ was distilled over $\mathrm{CaH}_{2}$ and other organic solvents used in this study were dried over appropriate drying agents by standard methods and distilled prior to use. All other chemicals used in this study were commercially available and were used without additional purification unless otherwise noted. 
3.3. General Procedure for the Coinage Metal-catalyzed Cycloisomerization of the 1-Hydroxyalkyl1,2-dienephosphonates $\mathbf{1}$

Metal salt catalyst $(0.15 \mathrm{mmol})$ was added to a solution of the 1-hydroxyalkyl-1,2dienephosphonate $1(3.0 \mathrm{mmol})$ in dry dichloromethane $(10 \mathrm{~mL})$. The mixture was stirred at room temperature and in the dark for the minutes indicated in the Table 3. Saturated sodium chloride solution was added to precipitate the silver ions. The product was extracted by chloroform. The organic layer was dried over anhydrous sodium sulfate. After evaporation of the solvent, the residue was chromatographed on a column (silica gel, Kieselgel Merck $60 \mathrm{~F}_{254}$ ) with a mixture of ethyl acetate and hexane (6:1) as an eluent to give the pure products $\mathbf{3}$ as oils, which had the following properties:

Dimethyl (5-ethyl-5-methyl-2,5-dihydrofuran-3-yl)phosphonate (3a). This compound was obtained as a yellow oil, yield 83\%. Rf 0.44; IR (neat, $\left.v_{\max }, \mathrm{cm}^{-1}\right)$ : $1128(\mathrm{C}-\mathrm{O}-\mathrm{C}), 1254(\mathrm{P}=\mathrm{O}), 1627(\mathrm{C}=\mathrm{C})$. ${ }^{1} \mathrm{H}-\mathrm{NMR}\left(250.1 \mathrm{MHz}\right.$ ): $\delta_{\mathrm{H}} 0.89\left(\mathrm{t}, J=7.4 \mathrm{~Hz}, 3 \mathrm{H}, \underline{\mathrm{Me}}-\mathrm{CH}_{2}\right), 1.32$ (s, 3H, Me-C), 1.60-1.72 (m, 2H, $\left.\mathrm{Me}-\underline{\mathrm{H}}_{2}\right), 3.76$ (d, $\left.J=12.2 \mathrm{~Hz}, 3 \mathrm{H}, \mathrm{MeO}\right), 4.73-4.77\left(\mathrm{~m}, 2 \mathrm{H}, \mathrm{CH}_{2} \mathrm{O}\right), 6.53-6.57(\mathrm{~m}, 1 \mathrm{H},=\mathrm{CH})$. ${ }^{13} \mathrm{C}-\mathrm{NMR}(62.9 \mathrm{MHz}) \delta_{\mathrm{C}} 8.6,25.2(J=2.0 \mathrm{~Hz}), 33.0(J=4.5 \mathrm{~Hz}), 52.5(J=5.6 \mathrm{~Hz}), 74.9(J=20.5 \mathrm{~Hz})$, $92.3(J=19.1 \mathrm{~Hz}), 127.5(J=195.9 \mathrm{~Hz}), 149.6(J=10.1 \mathrm{~Hz}) .{ }^{31} \mathrm{P}-\mathrm{NMR}(101.2 \mathrm{MHz}): \delta \mathrm{P} 15.9$. Anal. Calcd for $\mathrm{C}_{9} \mathrm{H}_{17} \mathrm{O}_{4} \mathrm{P}$ requires: C 49.09, H 7.78. Found: C 49.12, H 7.74.

Dimethyl (5-butyl-5-methyl-2,5-dihydrofuran-3-yl)phosphonate (3b). This compound was obtained as a yellow oil, yield 75\%. Rf 0.40; IR (neat, $\left.v_{\max }, \mathrm{cm}^{-1}\right)$ : $1120(\mathrm{C}-\mathrm{O}-\mathrm{C}), 1258(\mathrm{P}=\mathrm{O}), 1626(\mathrm{C}=\mathrm{C})$. ${ }^{1} \mathrm{H}-\mathrm{NMR}(600.1 \mathrm{MHz}): \delta_{\mathrm{H}} 0.88\left(\mathrm{t}, J=7.2 \mathrm{~Hz}, 3 \mathrm{H}, \underline{\left.\mathrm{Me}-\mathrm{CH}_{2}\right), 1.19-1.26,1.28-1.37,1.56-1.67}\right.$ (overlapping multiplets, $6 \mathrm{H},\left(\mathrm{CH}_{2}\right)_{3}-\mathrm{Me}$ ), 1.31 (s, 3H, Me-C), 3.75 (d, $\left.J=12.0 \mathrm{~Hz}, 3 \mathrm{H}, \mathrm{MeO}\right), 4.71-4.78$ $\left(\mathrm{m}, 2 \mathrm{H}, \mathrm{CH}_{2} \mathrm{O}\right), 6.54-6.57(\mathrm{~m}, 1 \mathrm{H},=\mathrm{CH}) .{ }^{13} \mathrm{C}-\mathrm{NMR}(150.9 \mathrm{MHz}) \delta_{\mathrm{c}} 14.1,23.1,25.5(\mathrm{~J}=2.1 \mathrm{~Hz})$, 26.7, $40.0(J=4.5 \mathrm{~Hz}), 52.6(J=5.7 \mathrm{~Hz}), 74.8(J=20.6 \mathrm{~Hz}), 92.1(J=19.2 \mathrm{~Hz}), 127.6(J=196.1 \mathrm{~Hz})$, $149.8(J=10.1 \mathrm{~Hz}) .{ }^{31} \mathrm{P}-\mathrm{NMR}(242.9 \mathrm{MHz}): \delta \mathrm{P} 16.0$. Anal. Calcd for $\mathrm{C}_{11} \mathrm{H}_{21} \mathrm{O}_{4} \mathrm{P}$ requires: C 53.22, $\mathrm{H}$ 8.53. Found: C 53.18, H 8.55.

Dimethyl (1-oxaspiro[4.5]dec-3-en-3-yl)phosphonate (3c). This compound was obtained as an orange oil, yield 73\%. Rf 0.60; IR (neat, vmax, $\mathrm{cm}^{-1}$ ): 1126 (C-O-C), $1257(\mathrm{P}=\mathrm{O}), 1625$ (C=C). ${ }^{1} \mathrm{H}-\mathrm{NMR}$ (250.1 MHz): $\delta_{\mathrm{H}} 1.22-1.45,1.4-1.72,1.8-2.02$ (overlapping multiplets, $\left.10 \mathrm{H},\left(\mathrm{CH}_{2}\right)_{5}\right), 3.77(\mathrm{~d}$, $J=12.5 \mathrm{~Hz}, 3 \mathrm{H}, \mathrm{MeO}), 4.73-4.75\left(\mathrm{~m}, 2 \mathrm{H}, \mathrm{CH}_{2} \mathrm{O}\right), 6.72-6.75(\mathrm{~m}, 1 \mathrm{H},=\mathrm{CH}) .{ }^{13} \mathrm{C}-\mathrm{NMR}(62.9 \mathrm{MHz}) \delta \mathrm{C}$ 23.4, 25.8, $35.4(J=4.5 \mathrm{~Hz}), 52.6(J=5.6 \mathrm{~Hz}), 73.8(J=20.8 \mathrm{~Hz}), 91.4(J=19.1 \mathrm{~Hz}), 126.4 .5$ $(J=196.2 \mathrm{~Hz}), 149.9(J=9.8 \mathrm{~Hz}) .{ }^{31} \mathrm{P}-\mathrm{NMR}(101.2 \mathrm{MHz}): \delta \mathrm{P} 17.1$. Anal. Calcd for $\mathrm{C}_{11} \mathrm{H}_{19} \mathrm{O}_{4} \mathrm{P}$ requires: C 53.65, H 7.78. Found: C 53.62, H 7.70.

Dimethyl (2-methyl-1-oxaspiro[4.5]dec-3-en-3-yl)phosphonate (3d). This compound was obtained as an orange oil, yield 77\%. Rf 0.59; IR (neat, $\left.v_{\max }, \mathrm{cm}^{-1}\right)$ : $1119(\mathrm{C}-\mathrm{O}-\mathrm{C}), 1251(\mathrm{P}=\mathrm{O}), 1624(\mathrm{C}=\mathrm{C})$. ${ }^{1} \mathrm{H}-\mathrm{NMR}(600.1 \mathrm{MHz}): \delta_{\mathrm{H}} 1.21-1.31,1.34-1.52,1.68-1.89$ (overlapping multiplets, $10 \mathrm{H},\left(\mathrm{CH}_{2}\right) 5$ ), $1.38(\mathrm{~d}, J=6.4 \mathrm{~Hz}, 3 \mathrm{H}, \underline{\mathrm{Me}}-\mathrm{CH}), 3.75(\mathrm{~d}, J=11.2 \mathrm{~Hz}, 3 \mathrm{H}, \mathrm{MeO}), 5.01-5.05(\mathrm{~m}, 1 \mathrm{H}, \mathrm{Me}-\mathrm{C} \underline{\mathrm{H}})$, 6.75-6.79 (m, 1H, =CH). ${ }^{13} \mathrm{C}-\mathrm{NMR}(150.9 \mathrm{MHz}) \delta_{\mathrm{c}} 20.5(J=9.9 \mathrm{~Hz}), 20.6(J=4.5 \mathrm{~Hz}), 23.1,26.8$, $34.9(J=4.6 \mathrm{~Hz}), 52.5(J=5.7 \mathrm{~Hz}), 74.2(J=20.5 \mathrm{~Hz}), 91.9(J=19.3 \mathrm{~Hz}), 127.0(J=196.0 \mathrm{~Hz})$, 
$149.7(J=10.0 \mathrm{~Hz}) .{ }^{31} \mathrm{P}-\mathrm{NMR}(242.9 \mathrm{MHz}): \delta \mathrm{P}$ 17.0. Anal. Calcd for $\mathrm{C}_{12} \mathrm{H}_{21} \mathrm{O}_{4} \mathrm{P}$ requires: C 55.38, H 8.13. Found: C 55.44, H 8.09.

Dimethyl (5-butyl-2,2,5-trimethyl-2,5-dihydrofuran-3-yl)phosphonate (3e). This compound was obtained as a yellow oil, yield 74\%. R $\mathrm{R}_{\mathrm{f}}$ 0.56; IR (neat, $v_{\max }, \mathrm{cm}^{-1}$ ): 1117 (C-O-C), $1257(\mathrm{P}=\mathrm{O}), 1622$ $(\mathrm{C}=\mathrm{C}) .{ }^{1} \mathrm{H}-\mathrm{NMR}(600.1 \mathrm{MHz}): \delta_{\mathrm{H}} 0.88\left(\mathrm{t}, J=7.1 \mathrm{~Hz}, 3 \mathrm{H}, \underline{\mathrm{Me}}-\mathrm{CH}_{2}\right), 1.19-1.39,1.41-1.53,1.56-1.65$ (overlapping multiplets, 6H, Me- $\left.\left(\mathrm{CH}_{2}\right)_{3}\right), 1.33$ (s, 3H, Me-C), 1.44, 1.46 (ss, 6H, Me $2 \mathrm{C}$ ), 3.76 (d, $J=11.2 \mathrm{~Hz}, 3 \mathrm{H}, \mathrm{MeO}), 6.57-6.59(\mathrm{~m}, 1 \mathrm{H},=\mathrm{CH}) .{ }^{13} \mathrm{C}-\mathrm{NMR}(150.9 \mathrm{MHz}) \delta_{\mathrm{C}} 14.2,23.5,25.7(\mathrm{~J}=2.0 \mathrm{~Hz})$, 27.1, 28.5, 28.7, $41.1(J=4.6 \mathrm{~Hz}), 52.5(J=5.8 \mathrm{~Hz}), 74.9(J=20.4 \mathrm{~Hz}), 89.7(J=19.2 \mathrm{~Hz}), 127.1$ $(J=196.1 \mathrm{~Hz}), 150.3(J=10.1 \mathrm{~Hz}) .{ }^{31} \mathrm{P}-\mathrm{NMR}(242.9 \mathrm{MHz}): \delta \mathrm{P} 17.2$. Anal. Calcd for $\mathrm{C}_{13} \mathrm{H}_{25} \mathrm{O}_{4} \mathrm{P}$ requires: C 56.51, H 9.12. Found: C 56.57, H 9.17.

\subsection{General Procedure for the Coinage Metal-catalyzed Cycloisomerization of the}

2-Diphenylphosphinoyl-2,3-dien-1-ols 2a-c and the 3-Diphenylphosphinoyl-3,4-dien-2-ols 2d,e

Metal salt catalyst $(0.15 \mathrm{mmol})$ was added to a solution of the 2-diphenylphosphinoyl-2,3-dien-1-ols 2a-c or the 3-diphenylphosphinoyl-3,4-dien-2-ols $\mathbf{2 d , e ~}(3.0 \mathrm{mmol})$ in dry dichloromethane $(10 \mathrm{~mL})$. The mixture was stirred at room temperature and in the dark for the minutes indicated in the Table 3. Saturated sodium chloride solution was added to precipitate the metal ions. The product was extracted by dichloromethane. The organic layer was dried over anhydrous sodium sulfate. The solvent was removed using a rotatory evaporator and the residue was purified by column chromatography (silica gel, Kieselgel Merck $60 \mathrm{~F}_{254}$ ) with a mixture of ethyl acetate and hexane (5:1). The pure products 4 had the following properties:

Diphenyl (5-ethyl-5-methyl-2,5-dihydrofuran-3-yl) phosphine oxide (4a). This compound was obtained as a colourless oil, yield 85\%. Rf 0.58; IR (neat, $\left.v_{\max }, \mathrm{cm}^{-1}\right)$ : $1121(\mathrm{C}-\mathrm{O}-\mathrm{C}), 1174(\mathrm{P}=\mathrm{O}), 1436,1483$ $(\mathrm{Ph}), 1620(\mathrm{C}=\mathrm{C}) .{ }^{1} \mathrm{H}-\mathrm{NMR}(600.1 \mathrm{MHz}): \delta_{\mathrm{H}} 0.91\left(\mathrm{t}, J=7.5 \mathrm{~Hz}, 3 \mathrm{H}, \underline{\mathrm{Me}}-\mathrm{CH}_{2}\right), 1.33$ (s, 3H, Me-C),

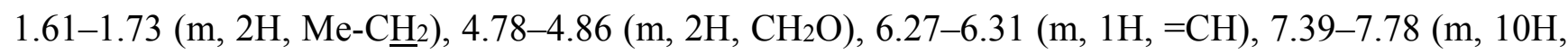
2Ph). ${ }^{13} \mathrm{C}-\mathrm{NMR}(150.9 \mathrm{MHz}) \delta \mathrm{C} 8.98,25.3(\mathrm{~J}=2.1 \mathrm{~Hz}), 33.0(J=4.4 \mathrm{~Hz}), 75.5(J=17.1 \mathrm{~Hz}), 92.7$ $(J=14.9 \mathrm{~Hz}), 133.5(J=104.0 \mathrm{~Hz}), 128.1-132.9,149.6(J=7.3 \mathrm{~Hz}) .{ }^{31} \mathrm{P}-\mathrm{NMR}(242.9 \mathrm{MHz}): \delta$ P 22.2. Anal. Calcd for $\mathrm{C}_{19} \mathrm{H}_{21} \mathrm{O}_{2} \mathrm{P}$ requires: C 73.06, H 6.78. Found: C 73.02, H 6.83.

Diphenyl (5-butyl-5-methyl-2,5-dihydrofuran-3-yl) phosphine oxide (4b). This compound was obtained as a colourless oil, yield 85\%. $\mathrm{R}_{\mathrm{f}}$ 0.52; IR (neat, $\left.v_{\max }, \mathrm{cm}^{-1}\right): 1120(\mathrm{C}-\mathrm{O}-\mathrm{C}), 1178(\mathrm{P}=\mathrm{O}), 1437,1492$ $(\mathrm{Ph}), 1618(\mathrm{C}=\mathrm{C}) .{ }^{1} \mathrm{H}-\mathrm{NMR}(600.1 \mathrm{MHz}): \delta_{\mathrm{H}} 0.89$ (t, $J=7.1 \mathrm{~Hz}, 3 \mathrm{H}, \underline{\left.\mathrm{Me}-\mathrm{CH}_{2}\right), 1.22-1.41,1.59-1.69}$ (overlapping multiplets, 6H, ( $\left.\left.\underline{\mathrm{H}}_{2}\right)_{3}-\mathrm{Me}\right), 1.34$ (s, 3H, Me-C), 4.77-4.84 (m, 2H, $\mathrm{CH}_{2} \mathrm{O}$ ), 6.28-6.31 (m, $1 \mathrm{H},=\mathrm{CH}), 7.47-7.72(\mathrm{~m}, 10 \mathrm{H}, 2 \mathrm{Ph}) .{ }^{13} \mathrm{C}-\mathrm{NMR}(150.9 \mathrm{MHz}) \delta \mathrm{c} 14.1,23.8,25.0,25.8(\mathrm{~J}=2.0 \mathrm{~Hz})$, $40.2(J=4.6 \mathrm{~Hz}), 75.3(J=17.0 \mathrm{~Hz}), 92.4(J=15.0 \mathrm{~Hz}), 128.7-132.4,133.7(J=103.6 \mathrm{~Hz}), 149.7$ $(J=7.3 \mathrm{~Hz}) .{ }^{31} \mathrm{P}-\mathrm{NMR}(242.9 \mathrm{MHz})$ : $\delta \mathrm{P} 21.0$. Anal. Calcd for $\mathrm{C}_{21} \mathrm{H}_{25} \mathrm{O}_{2} \mathrm{P}$ requires: $\mathrm{C} 74.10, \mathrm{H} 7.40$. Found: C 74.05, H 7.46.

Diphenyl (1-oxaspiro[4.5]dec-3-en-3-yl) phosphine oxide (4c). This compound was obtained as a yellow oil, yield 82\%. Rf 0.55; IR (neat, $v_{\max }, \mathrm{cm}^{-1}$ ): $1120(\mathrm{C}-\mathrm{O}-\mathrm{C}), 1169(\mathrm{P}=\mathrm{O}), 1439,1491(\mathrm{Ph})$, 
$1622(\mathrm{C}=\mathrm{C}) .{ }^{1} \mathrm{H}-\mathrm{NMR}(600.1 \mathrm{MHz}): \delta_{\mathrm{H}} 1.32-1.38,1.47-1.55,1.64-1.74$ (overlapping multiplets, $10 \mathrm{H}$, $\left.\left(\mathrm{CH}_{2}\right)_{5}\right), 4.77-4.79\left(\mathrm{~m}, 2 \mathrm{H}, \mathrm{CH}_{2} \mathrm{O}\right), 6.45-6.50(\mathrm{~m}, 1 \mathrm{H},=\mathrm{CH}), 7.48-7.70(\mathrm{~m}, 10 \mathrm{H}, 2 \mathrm{Ph}) .{ }^{13} \mathrm{C}-\mathrm{NMR}$ $(150.9 \mathrm{MHz}) \delta_{\mathrm{C}} 23.0,25.3,35.8(J=4.4 \mathrm{~Hz}), 74.3(J=17.0 \mathrm{~Hz}), 91.6(J=14.8 \mathrm{~Hz}), 128.3-134.2$, $133.0(J=103.7 \mathrm{~Hz}), 149.8(J=7.3 \mathrm{~Hz}) .{ }^{31} \mathrm{P}-\mathrm{NMR}(242.9 \mathrm{MHz})$ : $\delta \mathrm{P} 21.2$. Anal. Calcd for $\mathrm{C}_{21} \mathrm{H}_{23} \mathrm{O}_{2} \mathrm{P}$ requires: C 74.54, H 6.85. Found: C 74.50, H 6.79.

Diphenyl (2-methyl-1-oxaspiro[4.5]dec-3-en-3-yl) phosphine oxide (4d). This compound was obtained as a yellow oil, yield 84\%. $\mathrm{R}_{\mathrm{f}}$ 0.47; IR (neat, $\left.v_{\max }, \mathrm{cm}^{-1}\right)$ : $1119(\mathrm{C}-\mathrm{O}-\mathrm{C}), 1173(\mathrm{P}=\mathrm{O}), 1439,1485(\mathrm{Ph})$, $1621(\mathrm{C}=\mathrm{C}) .{ }^{1} \mathrm{H}-\mathrm{NMR}(600.1 \mathrm{MHz}): \delta_{\mathrm{H}} 1.18(\mathrm{~d}, J=6.4 \mathrm{~Hz}, 3 \mathrm{H}, \underline{\mathrm{Me}}-\mathrm{CH}), 1.32-1.38,1.42-1.54,1.55-1.64$ (overlapping multiplets, $10 \mathrm{H},\left(\mathrm{CH}_{2}\right)$ ) $), 5.06-5.09(\mathrm{~m}, 1 \mathrm{H}, \mathrm{Me}-\mathrm{C} \underline{\mathrm{H}}), 6.97-6.96(\mathrm{~m}, 1 \mathrm{H},=\mathrm{CH}), 7.30-7.69(\mathrm{~m}$, 10H, 2Ph). ${ }^{13} \mathrm{C}-\mathrm{NMR}(150.9 \mathrm{MHz}) \delta_{\mathrm{C}} 20.2(J=9.8 \mathrm{~Hz}), 20.5(J=4.6 \mathrm{~Hz}), 22.2,26.5,34.7(\mathrm{~J}=4.7 \mathrm{~Hz})$, $82.4(J=15.8 \mathrm{~Hz}), 89.8(J=15.3 \mathrm{~Hz}), 128.4-135.0,136.8(J=102.4 \mathrm{~Hz}), 149.7(J=7.8 \mathrm{~Hz}) .{ }^{31} \mathrm{P}-\mathrm{NMR}$ (242.9 MHz): $\delta \mathrm{P} 22.2$. Anal. Calcd for $\mathrm{C}_{22} \mathrm{H}_{25} \mathrm{O}_{2} \mathrm{P}$ requires: C 74.98, H 7.15. Found: C 75.05, H 7.11.

Diphenyl (5-butyl-2,2,5-trimethyl-2,5-dihydrofuran-3-yl) phosphine oxide (4e). This compound was obtained as a colourless oil, yield 82\%. $\mathrm{R}_{\mathrm{f}}$ 0.46; IR (neat, $v_{\max }, \mathrm{cm}^{-1}$ ): $1115(\mathrm{C}-\mathrm{O}-\mathrm{C}), 1163(\mathrm{P}=\mathrm{O}), 1438$, $1483(\mathrm{Ph}), 1624(\mathrm{C}=\mathrm{C}) .{ }^{1} \mathrm{H}$ NMR $(600.1 \mathrm{MHz}): \delta_{\mathrm{H}} 0.87\left(\mathrm{t}, J=7.2 \mathrm{~Hz}, 3 \mathrm{H}, \underline{\mathrm{Me}}-\mathrm{CH}_{2}\right), 1.27-1.36,1.49-1.54$ (overlapping multiplets, $\left.6 \mathrm{H},\left(\mathrm{C}_{2}\right)_{3}-\mathrm{Me}\right), 1.32$ (s, 3H, Me-C), 1.45, 1.48 (ss, 6H, $\mathrm{Me}_{2} \mathrm{C}$ ), 6.90-6.96 (m, $1 \mathrm{H},=\mathrm{CH}), 7.46-7.79(\mathrm{~m}, 10 \mathrm{H}, 2 \mathrm{Ph}) .{ }^{13} \mathrm{C}-\mathrm{NMR}(150.9 \mathrm{MHz}) \delta_{\mathrm{C}} 14.1,23.8,25.0,26.3(\mathrm{~J}=2.1 \mathrm{~Hz})$, 27.5, 27.7, $40.3(J=4.7 \mathrm{~Hz}), 83.5(J=16.0 \mathrm{~Hz}), 91.0(J=14.5 \mathrm{~Hz}), 128.6-134.7,133.5(J=103.4 \mathrm{~Hz})$, $144.9(J=7.6 \mathrm{~Hz}) .{ }^{31} \mathrm{P}-\mathrm{NMR}(242.9 \mathrm{MHz})$ : $\delta \mathrm{P} 22.1$. Anal. Calcd for $\mathrm{C}_{23} \mathrm{H}_{29} \mathrm{O}_{2} \mathrm{P}$ requires: $\mathrm{C} 74.98, \mathrm{H}$ 7.93. Found: C 74.93, H 8.01.

\section{Conclusions}

In conclusion, we have developed a coinage metal-catalyzed cycloisomerization of phosphorylated $\alpha$-hydroxyallenes, which provides an efficient route to 3-phosphorylated 2,5-dihydrofurans. Due to the ready availability of the starting materials and the catalyst, the convenient operation and mild conditions (room temperature, short reaction time), the very good yields and the usefulness of the resulting 2,5-dihydrofuran products, the reaction shows potential and will be useful in organic synthesis as well in the application of the method in target-oriented synthesis. Further investigation on the chemistry of other phosphorylated allenols for the synthesis of different heterocyclic systems is being intensively carried out in our laboratory. Moreover, results of an initial investigation of the biological activity of the compounds prepared were encouraging, and the antibacterial and antifungal activities of selected compounds are now under investigation in our University.

\section{Acknowledgments}

Financial support of our work by the Research Fund of the Konstantin Preslavsky University of Shumen (Projects Nos. RD-08-208/2014 and RD-08-248/2015), National Research Fund of Bulgaria (Project No. DRNF-02-13/2009) and Human Resources Development Operational Programme of the European Union (BG051PO001-3.3.06-0003/2012) is gratefully acknowledged. 


\section{Author Contributions}

V.C.C. proposed the subject, designed the study and offered necessary guidance to I.E.I. and I.K.I. V.C.C. and I.K.I. conceived and designed the experiments. I.E.I. and I.K.I. performed the experiments under the supervision of the lead author V.C.C. who analyzed the spectral data and wrote the manuscript.

\section{Conflicts of Interest}

The authors declare no conflict of interest.

\section{References}

1. Heaney, H.; Ahn, J.S. Five-membered rings with one heteroatom and fused carbocyclic derivatives. In Comprehensive Heterocyclic Chemistry II; Katritzky, A.R., Rees, C.W., Scriven, E.F.V., Eds.; Pergamon Press: Oxford, UK, 1996; Volume 2, pp. 297-436.

2. Eicher, T.; Hauptmann, S. The Chemistry of Heterocycles: Structure, Reactions, Syntheses, and Applications; Wiley-VCH: Weinheim, Germany, 2003.

3. Lipshutz, B.H. Five-membered heteroaromatic rings as intermediates in organic synthesis. Chem. Rev. 1986, 86, 795-819.

4. Ganguli, M.; Burka, L.T.; Harris, T.M. Structural studies of the mycotoxin verrucosidin. J. Org. Chem. 1984, 49, 3762-3766.

5. Franck, B.; Gehrken, H.-P. Citreoviridins from Aspergillus terreus. Angew. Chem. Int. Ed. 1980, $19,461-462$.

6. Yamaguchi, R.; Miyake, N.; Kato, K.; Ueno, Y. Peroxyl-radical reaction of retinyl acetate in solution. Biosci. Biotechnol. Biochem. 1992, 56, 1529-1532.

7. Boivin, T.L. B. Synthetic routes to tetrahydrofuran, tetrahydropyran, and spiroketal units of polyether antibiotics and a survey of spiroketals of other natural products. Tetrahedron 1987, 43, 3309-3362.

8. Koert, U.; Stein, M.; Wagner, H. Bidirectional and convergent routes to oligo(tetrahydrofurans). Chem. Eur. J. 1997, 3, 1170-1180.

9. Perron, F.; Albizati, K.F. Chemistry of spiroketals. Chem. Rev. 1989, 89, 1617-1661.

10. Erdsack, J.; Krause, N. Synthesis of furanomycin derivatives by Gold-catalyzed cycloisomerization of $\alpha$-hydroxyallenes. Synthesis 2007, 3741-3750, doi:10.1055/s-2007-990860.

11. Review on synthesis of dihydrofurans: Kilroy, T.G.; O’Sullivan, T.P.; Guiry, P.J. Synthesis of dihydrofurans substituted in the 2-position. Eur. J. Org. Chem. 2005, 4929-4949.

12. Buzas, A.; Istrate, F.; Gagosz, F. Gold(I)-catalyzed stereoselective formation of functionalized 2,5-dihydrofurans. Org. Lett. 2006, 8, 1957-1959.

13. Liu, Y.; Song, F.; Song, Z.; Liu, M.; Yan, B. Gold-catalyzed cyclization of (Z)-2-en-4-yn-1-ols: Highly efficient synthesis of fully substituted dihydrofurans and furans. Org. Lett. 2005, 7, 5409-5412.

14. Zimmer, R.; Dinesh, C.U.; Nadanan, E.; Hhan, F.A. Palladium-catalyzed reactions of allenes. Chem. Rev. 2000, 100, 3067-3125.

15. Olsson, L.-I.; Claesson, A. Synthesis of 2,5-dihydrofurans and 5,6-dihydro-2H-pyrans by silver(I)catalyzed cyclization of allenic alcohols. Synthesis 1979, 743-745, doi:10.1055/s-1979-28825. 
16. Nikam, S.S.; Chu, K.H.; Wang, K.K. The cyclization of trimethylsilyl-substituted $\alpha$-allenic alcohols to 3-(trimethylsilyl)-2,5-dihydrofurans and their facile autoxidation to 3-(trimethylsilyl)furans or 4-(trimethylsilyl)-2(5H)-furanones. J. Org. Chem. 1986, 51, 745-747.

17. Marshall, J.A.; Sehon, C.A. Synthesis of furans and 2,5-dihydrofurans by Ag(I)-catalyzed isomerization of allenones, akynyl allylic alcohols, and allenyl carbinols. J. Org. Chem. 1995, 60, 5966-5968.

18. Marshall, J.A.; Yu, R.H.; Perkins, J.F. Diastereo- and enantioselective synthesis of allenylcarbinols through SE2' addition of transient nonracemic propargylic stannanes to aldehydes. J. Org. Chem. 1995, 60, 5550-5555.

19. Chilot, J.-J.; Doutheau, A.; Gore, J. Heterocyclisation de diols $\beta \gamma$ '-alleniques. Tetrahedron Lett. 1982, 23, 4693-4696.

20. Gelin, R.; Gelin, S.; Albrand, M. Oxymercuration-demercuration d'alcools $\alpha$-alleniques. Bull. Soc. Chim. Fr. 1972, 1946-1949.

21. Uemura, K.; Shiraishi, D.; Noziri, M.; Inoue, Y. Preparation of cyclic carbonates from alkadienols, $\mathrm{CO}_{2}$, and aryl or vinylic halides catalyzed by a palladium complex. Bull. Chem. Soc. Jpn. 1999, 72, 1063-1069.

22. Kang, S.-K.; Baik, T.-G.; Kulak, A.N. Palladium(0)-catalyzed coupling cyclization of functionalized allenes with hypervalent iodonium salts. Synlett 1999, 324-326, doi:10.1055/s-1999-2613.

23. Kang, S.-K.; Yamaguchi, T.; Pyun, S.-J.; Lee, Y.-T.; Baik, T.-G. Palladium-catalyzed arylation of $\alpha$-allenic alcohols with hypervalent iodonium salts: Synthesis of epoxides and diol cyclic carbonates. Tetrahedron Lett. 1998, 39, 2127-2130.

24. Ma, S.; Gao, W. Efficient synthesis of 4-(2-alkenyl)-2,5-dihydrofurans via $\mathrm{PdCl}_{2}$-catalyzed coupling-cyclization reaction of 2,3-allenols with allylic halides. Tetrahedron Lett. 2000, 41, 8933-8936.

25. Ma, S.; Gao, W. Efficient Synthesis of 4-(2'-alkenyl)-2,5-dihydrofurans and 5,6-dihydro-2H-pyrans via the Pd-catalyzed cyclizative coupling reaction of 2,3- or 3,4-allenols with allylic halides. J. Org. Chem. 2002, 67, 6104-6112.

26. Yoneda, E.; Kaneko, T.; Zhang, S.-W.; Onitsuka, K.; Takahashi, S. Ruthenium-catalyzed cyclic carbonylation of allenyl alcohols. Selective synthesis of $\gamma$ - and $\delta$-lactones. Org. Lett. 2000, 2, 441-443.

27. Trost, B.M.; Pinkerton, A.B. A Ruthenium-catalyzed alkylative cycloetherification. J. Am. Chem. Soc. 1999, 121, 10842-10843.

28. Hoffmann-Röder, A.; Krause, N. The golden gate to catalysis. Org. Biomol. Chem. 2005, 3, 387-391.

29. Widenhoefer, R.A.; Han, X. Gold-catalyzed hydroamination of C-C multiple bonds. Eur. J. Org. Chem. 2006, 4555-4563, doi:10.1002/ejoc.200600399.

30. Hashmi, A.S. K.; Hutchings, G.J. Gold catalysis. Angew. Chem. Int. Ed. 2006, 45, 7896-7936.

31. Jimenez-Nunez, E.; Echavarren, A.M. Molecular diversity through gold catalysis with alkynes. Chem. Commun. 2007, 333-343.

32. Gorin, D.J.; Toste, F.D. Relativistic effects in homogeneous Gold catalysis. Nature 2007, 446, 395-403.

33. Bongers, N.; Krause, N. Golden opportunities in stereoselective catalysis. Angew. Chem. Int. Ed. 2008, 47, 2178-2181. 
34. Hoffman-Roder, A.; Krause, N. Gold(III) chloride catalyzed cyclization of $\alpha$-hydroxyallenes to 2,5-dihydrofurans. Org. Lett. 2001, 3, 2537-2538.

35. Krause, N.; Hoffman-Roder, A.; Canisius, J. From amino acids to dihydrofurans: Functionalized allenes in modern organic synthesis. Synthesis 2002, 1759-1774, doi:10.1055/s-2002-33707.

36. Deutsch, C.; Gockel, B.; Hoffmann-Röder, A.; Krause, N. Golden opportunities in stereoselective catalysis: Optimization of chirality transfer and catalyst efficiency in the Gold-catalyzed cycloisomerization of $\alpha$-hydroxyallenes to 2,5-dihydrofurans. Synlett 2007, 1790-1794, doi:10.1055/s-2007-982561.

37. Gockel, B.; Krause, N. Golden times for allenes: Gold-catalyzed cycloisomerization of $\alpha$-hydroxyallenes to dihydropyrans. Org. Lett. 2006, 8, 4485-4488.

38. Morita, N.; Krause, N. Gold catalysis in organic synthesis: Efficient cycloisomerization of $\alpha$-aminoallenes to 3-pyrrolines. Org. Lett. 2004, 6, 4121-4123.

39. Morita, N.; Krause, N. Gold-Catalyzed cycloisomerization of $\alpha$-aminoallenes to 3-pyrrolines-optimization and mechanistic studies. Eur. J. Org. Chem. 2006, 4634-4641, doi:10.1002/ejoc.200600438.

40. Morita, N.; Krause, N. The First Gold-catalyzed C-S bond formation: Cycloisomerization of $\alpha$-thioallenes to 2,5-dihydrothiophenes. Angew. Chem. Int. Ed. 2006, 45, 1897-1899.

41. Angelov, C.M. Five-membered heterocyclization of phosphorus-containing allenes by their reaction with electrophiles_-possibilities and restrictions. Phosphorus Sulfur 1983, 15, 177-193.

42. Khusainova, N.G.; Pudovik, A.N. Phosphorylated allenes. Methods of synthesis and properties. Russ. Chem. Rev. 1987, 56, 564-578.

43. Alabugin, I.V.; Brel, V.K. Phosphorylated allenes: structure and interaction with electrophilic reagents. Russ. Chem. Rev. 1997, 66, 205-224.

44. Ma, S. Electrophilic addition and cyclization reactions of allenes. Acc. Chem. Res. 2009, 42, $1679-1688$.

45. Brel, V.K. Phosphonoallenes for building organophosphorus derivatives. Heteroatom Chem. 2006, 17, 547-556.

46. Brel, V.K. Synthesis and intramolecular cyclization of diethylphosphono-substituted allenic glycols. Synthesis 2001, 1539-1545, doi:10.1055/s-2001-16078.

47. Brel, V.K. Synthesis and cyclization of diethylphosphono-substituted $\alpha$-allenic alcohols to 4-(diethylphosphono)-2,5-dihydrofurans. Synthesis 1999, 463-466, doi:10.1055/s-1999-3420.

48. Brel, V.K.; Abramkin, E.V. Cyclization of allenyl phosphonates to 3-chloro-4-(diethylphosphono)2,5-dihydrofurans induced by $\mathrm{CuCl}_{2}$. Mendeleev Commun. 2002, 12, 64-66.

49. Brel, V.K.; Belsky, V.K.; Stash, A.I.; Zavodnik, V.E.; Stang, P.J. Synthesis and molecular structure of new unsaturated analogues of nucleotides containing six-membered rings. Eur. $J$. Org. Chem. 2005, 512-521.

50. Christov, V.C.; Ivanov, I.K. Alkatrienyl sulfoxides and sulfones. Part VI. Cheletropic addition of sulfur dioxide to 1- and 3-vinylallenyl sulfoxides and sulfones. Heterocycles 2004, 63, 2203-2206.

51. Christov, V.C.; Ivanov, I.K.; Ismailov, I.E. Bifunctionalized allenes. Part X. An electrophilic cyclization protocol for convenient highly regioselective synthesis of 3-sulfonyl-furan-2(5H)-ones from 2-sulfonyl-allenoates. Heterocycles 2013, 87, 1903-1916. 
52. Ivanov, I.K.; Parushev, I.D.; Christov, V.C. Bifunctionalized allenes. Part XII. Electrophilic cyclization and addition reactions of 4-sulfinylated or 4-sulfonylated allenoates. Phosphorus Sulfur 2014, 189, 1503-1513.

53. Ivanov, I.K.; Parushev, I.D.; Christov, V.C. Bifunctionalized allenes. Part XI. Competitive electrophilic cyclization and addition reactions of 4-phosphorylated allenecarboxylates. Heteroatom Chem. 2014, 25, 60-71.

54. Ismailov, I.E.; Ivanov, I.K.; Christov, V.C. Bifunctionalized allenes. Part XIII. A convenient and efficient method for regioselective synthesis of phosphorylated $\alpha$-hydroxyallenes with protected and unprotected hydroxy group. Molecules 2014, 19, 6309-6329.

55. Ismailov, I.E.; Ivanov, I.K.; Christov, V.C. Bifunctionalized allenes. Part XV. Synthesis of 2,5-dihydro-1,2-oxaphospholes by electrophilic cyclization reaction of phosphorylated a-hydroxyallenes. Molecules 2014, 19, 11056-11076.

Sample Availability: Samples of the compounds 1, 2, 3 and $\mathbf{4}$ are available from the authors.

(C) 2015 by the authors; licensee MDPI, Basel, Switzerland. This article is an open access article distributed under the terms and conditions of the Creative Commons Attribution license (http://creativecommons.org/licenses/by/4.0/). 